\title{
Study on Oil Pressure Characteristics and Trajectory Tracking Control in Shift Process of Wet-Clutch for Electric Vehicles
}

\author{
Junqiu Li, ${ }^{1}$ Yihe Wang, ${ }^{1}$ Jianwen Chen, ${ }^{2}$ and Zongping $\mathrm{He}^{2}$ \\ ${ }^{1}$ Collaborative Innovation Center of Electric Vehicles in Beijing, Beijing Institute of Technology, Beijing 100081, China \\ ${ }^{2}$ JIANGLU Machinery \& Electronics Group Co., Ltd., Xiangtan 411199, China
}

Correspondence should be addressed to Junqiu Li; lijunqiu@bit.edu.cn

Received 19 October 2015; Revised 22 January 2016; Accepted 11 February 2016

Academic Editor: Mitsuhiro Okayasu

Copyright (c) 2016 Junqiu Li et al. This is an open access article distributed under the Creative Commons Attribution License, which permits unrestricted use, distribution, and reproduction in any medium, provided the original work is properly cited.

Accurate control of oil pressure of wet-clutch is of great importance for improving shift quality. Based on dynamic models of twogear planetary transmission and hydraulic control system, a trajectory tracking model of oil pressure was built by sliding mode control method. An experiment was designed to verify the validity of hydraulic control system, through which the relationship between duty cycle of on-off valve and oil pressure of clutch was determined. The tracking effect was analyzed by simulation. Results showed that oil pressure could follow well the optimal trajectory and the shift quality was effectively improved.

\section{Introduction}

Electric vehicles are gaining popularity because of high energy efficiency, low emission, and diversified energy source [1]. To achieve high-efficiency and high-power, the integration of high speed motor and transmission box is becoming a trend of electric driving system. Two-gear planetary transmission and wet-clutch can be well matched with high speed motor, which has good application prospect and practical value in electric vehicles.

Because of high motor speed and large transformation ratio, the clutch works in a large range of speed difference in shift process, which greatly influences shift quality. It is required that vehicles should be smooth and steady in shift process; meanwhile the friction elements of clutch should work with low heat load. These two targets are both affected by clutch toque, which is decided by oil pressure if the physical structure of clutch is confirmed $[2,3]$. In previous researches, based on optimal control theory, with shifting jerk and sliding friction work selected as control targets, the authors have obtained optimal trajectory of oil pressure in shift process [4].

Pressure-flow modeling of wet-clutch is widely used to analyze shift quality $[5,6]$. In this paper, the hydraulic system model is built by mathematical analysis method to analyze oil pressure characteristics in shift process.
Proportional control method is widely applied in clutch pressure control $[7,8]$. However, complex road conditions in vehicle driving make strict demand on initial pressure and pressure change rate, and it is hard to acquire preferable shift quality. Fuzzy control method is widely accepted, and the combination of fuzzy adjustment of variable factors and proportion adjustment of coefficient can obtain better effect [9]. Due to the complex nonlinear characteristics of clutch, changeable liquid viscosity, and variable external load, there is a great necessity to work out a strategy with strong robustness and preferable tracking quality. On position tracking control, Zhang et al. [10] effectively overcame the delay of electromagnetic valve and realized accurate control of clutch engagement process by predictive control method. For the lack of theories on system stability and robustness, it is hard to obtain preferable control effect. Xue et al. [11] realized oil pressure tracking by fuzzy adaptive PID control method. However, the relationship between parameter characteristic and control objective in fuzzification process is not clear, so it is hard to adjust parameters and obtain optimal control parameters. With advantages of fast response, no need of online identification, insensitive to external disturbance, simple structure, and strong robustness, sliding mode control is especially applicable for complex nonlinear system [12, 13]. Aiming at nonlinear characteristics of oil pressure and unobservable characteristics of clutch toque, a sliding mode 


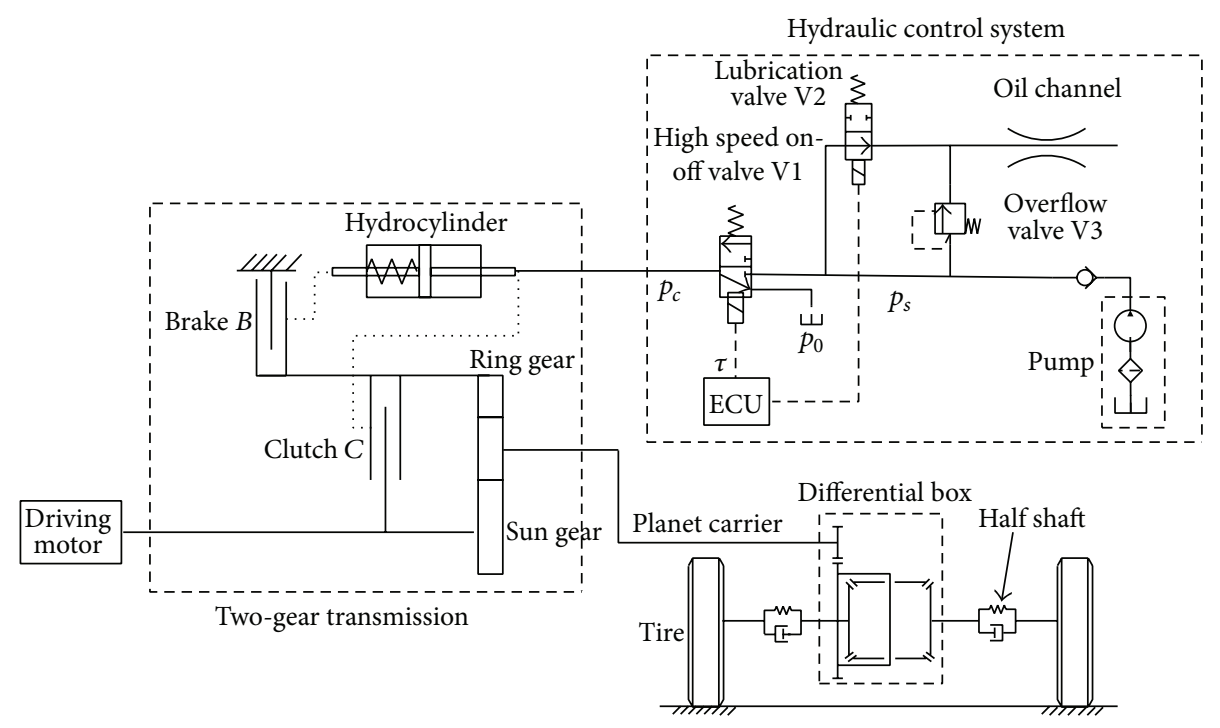

$p_{s}:$ system pressure

$p_{c}$ : shift pressure

$p_{0}$ : oil drainage pressure

FIGURE 1: Schematic diagram of system structure.

controller is designed to track optimal trajectory of shifting oil pressure in this paper, the accuracy and robustness of control system are well improved.

\section{Structure and Dynamic Modeling of Two-Gear Transmission}

The powertrain with a two-gear transmission and combined clutch is considered here, as schematically shown in Figure 1. The transmission system consists of a driving motor and twogear planetary transmission. The clutch $C$ and brake $B$ make up a combined clutch and they are structurally connected. By the control of high speed on-off valve V1 and lubrication valve V2, oil pressure could act on cylinder piston directly to complete shift action.

To realize downshift process, the Electric Control Unit (ECU) will enable oil charging circuit by closing V2 and opening V1. The rising pressure of oil will firstly push piston to get clutch $C$ disengaged, after a short free phase, along with the continuous movement of piston, the friction disks of brake $B$ are pressed tightly by piston; then brake $B$ is engaged and downshift process is completed. On 1st gear, the transmission ratio is given as $i_{1}=1+k$, where $k$ is the ratio of the teeth number of ring gear to that of sun gear. To realize upshift process, ECU will enable oil discharging circuit by closing V1 and opening V2, under the effect of return spring and gradually falling oil pressure, brake $B$ is disengaged; after a short free phase, piston is pushed to press the friction disk of clutch $C$ tightly to engage the clutch and upshift process is completed. At 2 nd gear, the transmission ratio is given as $i_{2}=1$.

2.1. Dynamic Modeling of Planetary Transmission. For simplification, the damping and elasticity of transmission shaft,

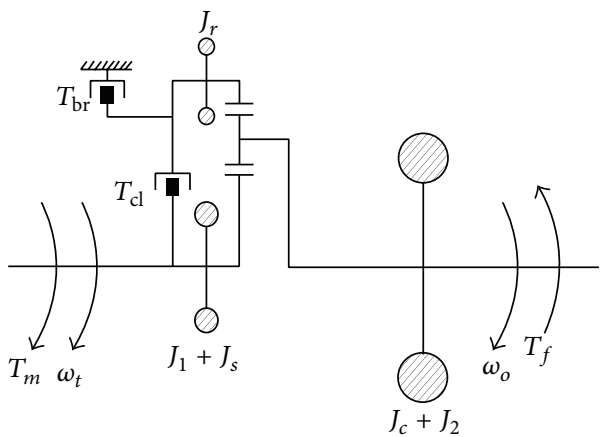

$\begin{array}{ll}m \text { : motor } & s \text { : sun gear } \\ f: \text { resistance force } & r: \text { ring gear } \\ t: \text { input } & c \text { : planet carrier } \\ o: \text { output } & p: \text { planet gear } \\ \text { cl: clutch } & 1: \text { driving motor } \\ \text { br: brake } & 2: \text { vehicle translational mass }\end{array}$

FIGURE 2: Dynamic model of planetary transmission.

bearings, and gear mesh are ignored, and all the components of powertrain are assumed as concentrated mass. The simplifications above will not produce too much influence to dynamic analysis of shift process [14]. The planetary transmission is modeled as shown in Figure 2, where $T$ represents the torque, $J$ the moment of inertia, and $\omega$ the angular velocity, and all subscripts of relevant parameters are shown in Figure 2.

The rotation angle of input shaft $\theta_{t}$ and rotation angle of output shaft $\theta_{o}$ are selected as generalized coordinates, expressed as $q_{1}=\theta_{t}, q_{2}=\theta_{o}$. 
According to principle of virtual work, the virtual work of transmission system is as follows:

$$
\sum \delta W=T_{m} \delta \theta_{t}-T_{\mathrm{br}} \delta \theta_{r}-T_{\mathrm{cl}}\left(\delta \theta_{t}-\delta \theta_{r}\right)-T_{f} \delta \theta_{\mathrm{o}},
$$

where $\delta \theta_{t}, \delta \theta_{r}$, and $\delta \theta_{o}$ are, respectively, the virtual rotation angle of input shaft, ring gear, and output shaft.

The motion law of planetary gear system is described as

$$
\left[\begin{array}{l}
\omega_{r} \\
\omega_{p}
\end{array}\right]=\left[\begin{array}{rr}
-\frac{1}{k} & \frac{k+1}{k} \\
-\frac{2}{k-1} & \frac{k+1}{k-1}
\end{array}\right]\left[\begin{array}{l}
\omega_{t} \\
\omega_{o}
\end{array}\right]=\left[\begin{array}{ll}
a_{11} & a_{12} \\
a_{21} & a_{22}
\end{array}\right]\left[\begin{array}{l}
\omega_{t} \\
\omega_{o}
\end{array}\right] .
$$

According to (2), the virtual rotation angle of ring gear can be expressed as

$$
\delta \theta_{r}=a_{11} \delta \theta_{t}+a_{12} \delta \theta_{o}
$$

By substituting in (3), (1) is presented as

$$
\begin{aligned}
\sum \delta W= & {\left[T_{m}-a_{11} T_{\mathrm{br}}-\left(1-a_{11}\right) T_{\mathrm{cl}}\right] \delta \theta_{t} } \\
& +\left[-a_{12} T_{\mathrm{br}}+a_{12} T_{\mathrm{cl}}-T_{f}\right] \delta \theta_{o} .
\end{aligned}
$$

Then the generalized forces are obtained:

$$
\begin{aligned}
& Q_{1}=T_{m}-a_{11} T_{\mathrm{br}}-a_{12} T_{\mathrm{cl}}, \\
& Q_{2}=-a_{12} T_{\mathrm{br}}+a_{12} T_{\mathrm{cl}}-T_{f} .
\end{aligned}
$$

According to kinetic energy theory, the kinetic energy of whole system is described as

$$
\begin{aligned}
E & =\frac{1}{2}\left[\left(J_{1}+J_{s}\right) \omega_{t}^{2}+J_{r} \omega_{r}^{2}+J_{p} \omega_{p}^{2}+m_{p}\left(\omega_{c} r_{c}\right)^{2}\right. \\
& \left.+\left(J_{c}+J_{2}\right) \omega_{c}^{2}\right],
\end{aligned}
$$

where $r_{c}$ is the equivalent radius of planet carrier and $m_{p}$ is total mass of planet carrier.

According to Lagrange equation,

$$
\frac{d}{d t}\left(\frac{\partial E}{\partial \dot{q}_{i}}\right)-\frac{\partial E}{\partial q_{i}}=Q_{i}, \quad(i=1,2) .
$$

Synthesizing (5)-(7), the dynamic modeling of transmission is presented as follows:

$$
\left[\begin{array}{ll}
J_{11} & J_{12} \\
J_{21} & J_{22}
\end{array}\right]\left[\begin{array}{c}
\dot{\omega}_{t} \\
\dot{\omega}_{o}
\end{array}\right]=\left[\begin{array}{c}
T_{m}-a_{11} T_{\mathrm{br}}-a_{12} T_{\mathrm{cl}} \\
-a_{12} T_{\mathrm{br}}+a_{12} T_{\mathrm{cl}}-T_{f}
\end{array}\right],
$$

where

$$
\begin{aligned}
& J_{11}=\left(J_{1}+J_{s}\right)+J_{r} a_{11}^{2}+J_{p} a_{12}^{2}, \\
& J_{12}=J_{21}=J_{r} a_{11} a_{12}+J_{p} a_{21} a_{22}, \\
& J_{22}=J_{r} a_{12}^{2}+J_{p} a_{22}^{2}+m_{p} r_{c}^{2}+J_{c}+J_{2} .
\end{aligned}
$$

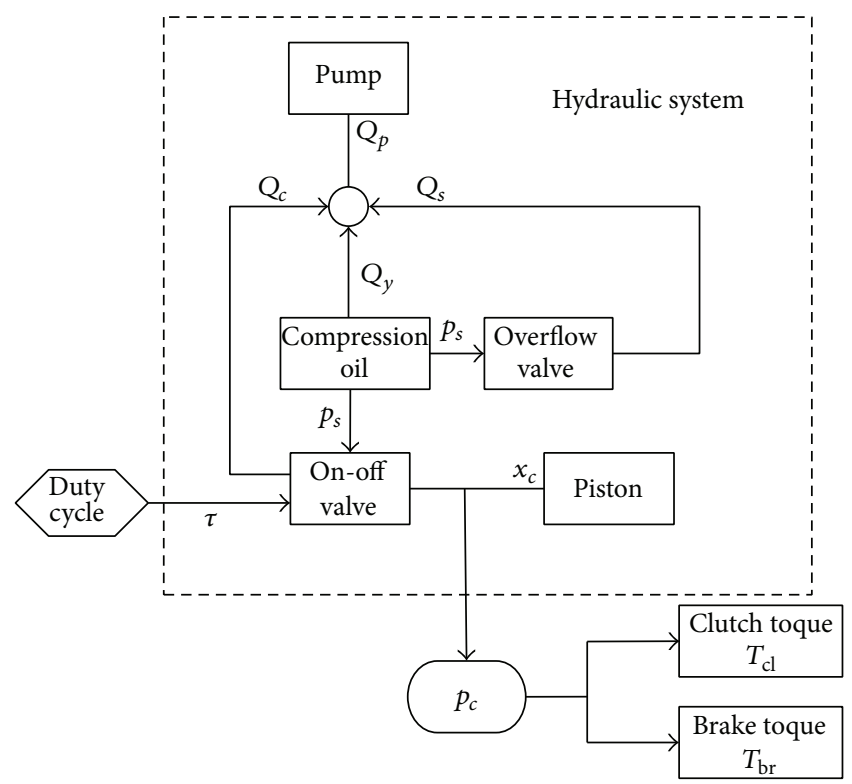

FIGURE 3: Modeling schematic of hydraulic system.

2.2. Hydraulic System Modeling. By analytic method, the mathematical model of hydraulic system is built. Oil tube leakage, cylinder leakage, and route loss are ignored in the model.

The modeling schematic is shown in Figure 3. Modeling process is divided into three steps:

(i) Build the relationship among oil pressure $p_{c}$, duty cycle $\tau$, system pressure $p_{s}$, and piston position $x_{c}$ by the flow model of high speed on-off valve.

(ii) Build the relationship between $p_{c}$ and $x_{c}$ by the motion differential equation of piston.

(iii) Build the relationship between $p_{c}$ and $p_{s}$ by the continuity equation of fluid flow.

Eventually a single input single output model of hydraulic system is built up and the relationship between $\tau$ and $p_{c}$ is determined; then the friction toque of combined clutch could be determined.

2.2.1. Flow Model of High Speed On-Off Valve. High speed on-off valve can only work at "on" or "off" state with high switching frequency controlled by Pulse Width Modulation (PWM). The average output flow $Q_{c}$ is decided by duty cycle $\tau$, presented as

$$
\begin{aligned}
Q_{c}= & \tau C_{d} A_{d} \sqrt{\frac{2}{\rho}}\left(\sqrt{\left(p_{s}-p_{c}\right)}+\sqrt{p_{c}-p_{0}}\right) \\
& -C_{d} A_{d} \sqrt{\frac{2\left(p_{c}-p_{0}\right)}{\rho}},
\end{aligned}
$$

where $C_{d}$ is the valve flow coefficient, $A_{d}$ is the valve throttling area, and $\rho$ is the oil density. 


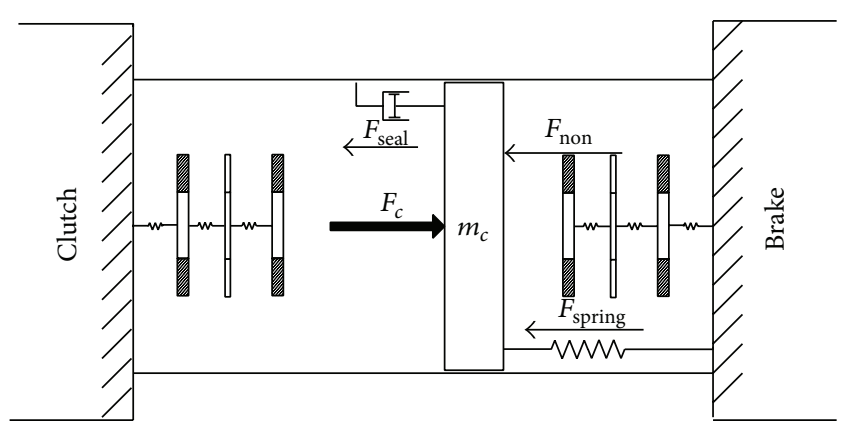

FIgURE 4: Force analysis of piston in cylinder.

Assume that oil temperature keeps constant, according to fluid mechanics, the flow into cylinder; in other words, the flow through on-off valve satisfies

$$
Q_{c}=\frac{A_{c} x_{c}+V_{0}}{\beta_{e}} \frac{d p_{c}}{d t}+A_{c} \dot{x}_{c}
$$

where $V_{0}$ is the initial volume of hydrocylinder, $\beta_{e}$ is oil elastic modulus, and $A_{c}$ is the sectional area of cylinder.

Synthesizing (10)-(11), the relationship among $p_{c}, \tau, p_{s}$, and $x_{c}$ could be expressed as

$$
\frac{d p_{c}}{d t}=\frac{\beta_{e}}{A_{c} x_{c}+V_{0}}\left[K_{1}\left(p_{c}\right) \tau-K_{2}\left(p_{c}\right)-A_{c} \dot{x}_{c}\right],
$$

where

$$
\begin{aligned}
& K_{1}\left(p_{c}\right)=C_{d} A_{d} \sqrt{\frac{2}{\rho}}\left(\sqrt{\left(p_{s}-p_{c}\right)}+\sqrt{p_{c}-p_{0}}\right), \\
& K_{2}\left(p_{c}\right)=C_{d} A_{d} \sqrt{\frac{2\left(p_{c}-p_{0}\right)}{\rho}} .
\end{aligned}
$$

2.2.2. Piston Motion Differential Equation. As shown in Figure 4, the forces of cylinder piston satisfy

$$
F_{c}-F_{\text {seal }}-F_{\text {spring }}-F_{\text {non }}=m_{c} \ddot{x}_{c}+c_{c} \dot{x}_{c} \text {, }
$$

where $F_{c}$ represents the static force of oil pressure, $F_{\text {seal }}$ the friction resistance of seal ring, $F_{\text {spring }}$ the force of return spring, and $F_{\text {non }}$ the spring reversion force caused by deformation of friction disks. $m_{c}$ is the effective mass of piston; $c_{c}$ is the viscous friction coefficient between cylinder and piston.

For further description,

$$
\begin{aligned}
F_{c} & =p_{c} A_{c}, \\
F_{\text {seal }} & =2 \pi \mu_{\text {seal }} b_{c}\left(R_{1 c}+R_{2 c}\right) p_{c}, \\
F_{\text {spring }} & =k_{c}\left(x_{c 0}+x_{c}\right),
\end{aligned}
$$

where $\mu_{\text {seal }}$ is the friction coefficient between seal ring and cylinder, $b_{c}$ is the thickness of seal ring, $R_{1 c}$ and $R_{2 c}$ are, respectively, inner and outer radius of piston, and $x_{c 0}$ is the initial compression amount of return spring. Consider the following:

$$
F_{\mathrm{non}}= \begin{cases}k_{\mathrm{non}} \cdot\left(x_{c}-0\right) & x_{c \mathrm{~min}} \leq x_{c} \leq 0 \\ 0 & 0<x_{c}<h_{p} \\ k_{\mathrm{non}} \cdot\left(x_{c}-h_{p}\right) & h_{p} \leq x_{c} \leq x_{c \max }\end{cases}
$$

where $k_{\text {non }}$ is the compression stiffness of friction disks deformation. Here we define the minimum and maximum displacement of piston as $x_{c \min }$ and $x_{c \text { max }}$. The two critical positions where the piston is without interaction with friction disks are defined as 0 and $h_{p}$, namely, the starting point and ending point of free phase.

Then the relationship between $p_{c}$ and $x_{c}$ is expressed as

$$
p_{c} A_{b}-F_{\text {non }}=m_{c} \ddot{x}_{c}+c_{c} \dot{x}_{c}+k_{c}\left(x_{c 0}+x_{c}\right) \text {, }
$$

where

$$
A_{b}=A_{c}-2 \pi \cdot \mu_{\text {seal }} \cdot b_{c} \cdot\left(R_{1 c}+R_{2 c}\right)
$$

2.2.3. Continuity Equation of Fluid Flow. According to liquid continuity [15], in downshift process, the flow equation of hydraulic system should be

$$
Q_{p}=Q_{c}+Q_{y}+Q_{s}
$$

where $Q_{p}$ is the total flow from hydraulic pump, $Q_{c}$ is the flow through high speed on-off valve, $Q_{y}$ is the flow caused by oil compression in connecting tube, and $Q_{s}$ is the flow through overflow valve. Consider the following:

$$
Q_{p}=n_{p} V_{p} \xi
$$

where $n_{p}$ is the rotational speed of oil pump, $V_{p}$ is the pump displacement, and $\xi$ is the volume efficiency of pump. Consider the following:

$$
Q_{y}=\frac{V_{y}}{\beta_{e}} \cdot \frac{d p_{s}}{d t}
$$

where $V_{y}$ is the volume of connecting tube. Consider the following:

$$
\begin{aligned}
& Q_{s} \\
& = \begin{cases}0 & p_{s}<p_{k} \\
\frac{C_{d s} \pi^{2} d_{s}^{3} \sin \alpha_{s}\left(p_{s}-p_{k}\right)}{4 k_{s}} \sqrt{\frac{2\left(p_{s}-p_{0}\right)}{\rho}} & p_{s} \geq p_{k},\end{cases}
\end{aligned}
$$

where $C_{d s}$ is the port flow coefficient of overflow valve, $d_{s}$ is the mean port diameter of overflow valve, $\alpha_{s}$ is the core half cone angle of overflow valve, and $p_{k}$ is the opening pressure of overflow valve. 
Synthesizing (11), (19)-(22), the relationship between $p_{c}$ and $p_{s}$ will be

$$
\begin{gathered}
\frac{V_{y}}{\beta_{e}} \frac{d p_{s}}{d t}+\frac{A_{c} x_{c}+V_{0}}{\beta_{e}} \frac{d p_{c}}{d t}+A_{c} \dot{x}_{c}-n_{p} V_{P} \xi=0, \\
p_{s}<p_{k} \\
\frac{V_{y}}{\beta_{e}} \frac{d p_{s}}{d t}+\frac{C_{d s} \pi^{2} d_{s}^{3} \sin \alpha_{s}\left(p_{s}-p_{k}\right)}{4 k_{s}} \sqrt{\frac{2\left(p_{s}-p_{0}\right)}{\rho}} \\
+\frac{A_{c} x_{c}+V_{0}}{\beta_{e}} \frac{d p_{c}}{d t}+A_{c} \dot{x}_{c}-n_{p} V_{P} \xi=0, \quad p_{s} \geq p_{k} .
\end{gathered}
$$

Till then, by (12), (17), and (23), the hydraulic system model is built up.

The toque transferred by combined clutch is given by (24) [16]. Downshift process includes three phases: clutch $C$ disengagement phase, free phase, and brake $B$ engagement phase. In clutch disengagement phase, $T_{\mathrm{cl}} \neq 0$ and $T_{\mathrm{br}}=0$; in free phase, $T_{\mathrm{cl}}=T_{\mathrm{br}}=0$; in brake engagement phase, $T_{\mathrm{cl}}=0$ and $T_{\mathrm{br}} \neq 0$. So the toque is transferred by combined clutch in the first and third phase only:

$$
T_{\mathrm{cl}}, T_{\mathrm{br}}=\mu N \frac{2\left(R_{2}^{3}-R_{1}^{3}\right)}{3\left(R_{2}^{2}-R_{1}^{2}\right)} \cdot\left[p_{c} A_{b}-k_{c}\left(x_{c 0}+x_{c}\right)\right],
$$

where $\mu$ is the friction coefficient of friction disk and it is assumed as a constant for simplification, $N$ is the number of friction pairs, and $R_{1}, R_{2}$ are, respectively, the inner and outer radius of friction disk. According to (24), there is a direct corresponding relationship between clutch toque and oil pressure.

\section{Sliding Mode Controller Design of Combined Clutch}

Combined clutch is the shifting actuating mechanism to realize toque transfer of vehicle driving system. Toque transfer and shift quality are decided by oil pressure characteristics of clutch. In this paper, sliding mode control method is used to realize trajectory tracking of oil pressure in each phase of shift process.

3.1. Principle of Sliding Mode Controller. To simplify the analysis and design of sliding mode control system, a linear switching surface is adopted:

$$
s=c e_{1}+e_{2} .
$$

Here a proper value of $c$ can ensure the accessibility and stability of the sliding mode control system. It can be determined by Hurwitz judgement and pole assignment method.

The exponential reaching law is selected, shown as

$$
\dot{s}=-\varepsilon \operatorname{sgn}(s)-k s, \quad k>0, \varepsilon>0 .
$$

Account the differential of (25)

$$
\dot{s}=c \dot{e}_{1}+\dot{e}_{2} .
$$

According to (26)-(27),

$$
-\varepsilon \operatorname{sgn}(s)-k s=c \dot{e}_{1}+\dot{e}_{2} .
$$

Through the state space equations of shift process, the relationship between deviation variables and control variables could be determined [17, 18]. By (28), the control variable could be calculated to track the optimal trajectory of oil pressure.

3.2. Sliding Mode Controller in Downshift Process. The oil pressure of the combined clutch in this paper is unable to be measured directly, so the tracking variable should be another measurable state variable rather than oil pressure itself.

3.2.1. In Clutch Disengagement Phase and Brake Engagement Phase. Motor speed is a measurable state variable linked to oil pressure in these two phases, so it is selected as tracking variable for these two phases.

Define the state variables as

$$
\begin{aligned}
& x_{1}=\omega_{m}, \\
& x_{2}=\dot{\omega}_{m} .
\end{aligned}
$$

According to (8), (12), and (24), the state space equation of tracking system is expressed as

$$
\begin{aligned}
& \dot{x}_{1}=x_{2}, \\
& \dot{x}_{2}=b_{1} \frac{d T_{m}}{d t}+b_{2}\left[K_{1}\left(p_{c}\right) \tau-K_{2}\left(p_{c}\right)\right] .
\end{aligned}
$$

For clutch disengagement phase,

$$
\begin{aligned}
& b_{1}=\frac{J_{22}}{J_{11} J_{22}-J_{12} J_{21}}, \\
& b_{2}=\frac{-z \mu R_{e} A_{b} \beta_{e} a_{12}\left(J_{12}+J_{22}\right)}{V_{0}\left(J_{11} J_{22}-J_{12} J_{21}\right)} .
\end{aligned}
$$

For brake engagement phase,

$$
\begin{aligned}
& b_{1}=\frac{J_{22}}{J_{11} J_{22}-J_{12} J_{21}}, \\
& b_{2}=\frac{z \mu R_{e} A_{b} \beta_{e}\left(a_{12} J_{12}-a_{11} J_{22}\right)}{V_{0}\left(J_{11} J_{22}-J_{12} J_{21}\right)} .
\end{aligned}
$$

Then define the reference variables as

$$
\begin{aligned}
& r_{1}=\omega_{m}^{*} \\
& r_{2}=\dot{\omega}_{m}^{*} .
\end{aligned}
$$

Consequently, the deviation variables are expressed as

$$
\begin{aligned}
& e_{1}=r_{1}-x_{1}, \\
& e_{2}=r_{2}-x_{2} .
\end{aligned}
$$


For a further comment,

$$
\begin{aligned}
& \dot{e}_{1}=e_{2}, \\
& \dot{e}_{2}=\ddot{r}_{1}-b_{1} \frac{d T_{m}}{d t}-b_{2}\left[K_{1}\left(p_{c}\right) \tau-K_{2}\left(p_{c}\right)\right] .
\end{aligned}
$$

Substituting (37) into (28),

$$
\begin{aligned}
-\varepsilon \operatorname{sgn}(s)-k s= & c e_{2}+\ddot{r}_{1}-b_{1} \frac{d T_{m}}{d t} \\
& -b_{2}\left[K_{1}\left(p_{c}\right) \tau-K_{2}\left(p_{c}\right)\right] .
\end{aligned}
$$

Finally,

$$
\begin{aligned}
\tau= & \frac{1}{b_{2} K_{1}\left(p_{c}\right)}\left[c e_{2}+\ddot{r}_{1}-b_{1} \frac{d T_{m}}{d t}+b_{2} K_{2}\left(p_{c}\right)\right. \\
& +\varepsilon \operatorname{sgn}(s)+k s] .
\end{aligned}
$$

Till then, on the basis of sliding mode control theory, the trajectory tracking of motor speed in clutch disengagement phase and brake engagement phase is realized. The trajectory of duty cycle of high speed on-off valve is obtained.

Here the proof of tracking stability is given.

Define the Lyapunov function as

$$
V=\frac{1}{2} s^{2}
$$

Then

$$
\begin{aligned}
\dot{V}= & s \cdot \dot{s} \\
= & s \\
& \quad\left\langle c e_{2}+\ddot{r}_{1}-b_{1} \frac{d T_{m}}{d t}-b_{2}\left[K_{1}\left(p_{c}\right) \tau-K_{2}\left(p_{c}\right)\right]\right\rangle .
\end{aligned}
$$

Substituting (39) into (41),

$$
\begin{aligned}
\dot{V} & =s \cdot\left\{c e_{2}+\ddot{r}_{1}-b_{1} \frac{d T_{m}}{d t}-b_{2}\left[K_{1}\left(p_{c}\right)\right.\right. \\
& \cdot \frac{1}{b_{2} K_{1}\left(p_{c}\right)}\left[c e_{2}+\ddot{r}_{1}-b_{1} \frac{d T_{m}}{d t}+b_{2} K_{2}\left(p_{c}\right)\right. \\
& \left.\left.+\varepsilon \operatorname{sgn}(s)+k s]-K_{2}\left(p_{c}\right)\right]\right\}=s \cdot[-\varepsilon \operatorname{sgn}(s) \\
& -k s]=-\varepsilon \cdot|s|-k s^{2}=-\left(\frac{\varepsilon}{2} \sqrt{V}+\frac{k}{2} V\right) \leq 0 .
\end{aligned}
$$

Proof is completed.

3.2.2. In Free Phase. Piston position is linked to oil pressure in this phase. To ensure the smoothness of piston at the point of disengagement and engagement, piston movement should be controlled reasonably. Consequently, the piston position is selected as tracking variable for free phase.
Let

$$
\begin{aligned}
& \ddot{x}_{c}=A t^{2}+B t+C, \\
& \dot{x}_{c}=\frac{1}{3} A t^{3}+\frac{1}{2} B t^{2}+C t+D \\
& x_{c}=\frac{1}{12} A t^{4}+\frac{1}{6} B t^{3}+\frac{1}{2} C t^{2}+D t+E
\end{aligned}
$$

where $t$ is the time of piston movement and $A, B, C, D, E$ are undetermined constants. To reduce the piston shock at the point of engagement and disengagement, the speed and acceleration of piston should be zero at these two points. Thus, the undetermined constants can be determined. The optimal trajectories of piston position $x_{c}^{*}, \dot{x}_{c}^{*}$, and $\ddot{x}_{c}^{*}$ can be determined.

Let

$$
\begin{aligned}
& x_{1}=\dot{x}_{c}, \\
& x_{2}=\ddot{x}_{c} .
\end{aligned}
$$

According to (12) and (17)

$$
\begin{aligned}
& \dot{x}_{1}=x_{2}, \\
& \dot{x}_{2}=M_{1} \tau-M_{2}-M_{3}-\frac{c_{c}}{m} x_{2}-\frac{k_{c}}{m} x_{1},
\end{aligned}
$$

where

$$
\begin{aligned}
& M_{1}=\frac{A_{b}}{m} \frac{\beta_{e}}{A_{c} x_{c}+V_{0}} K_{1}\left(p_{c}\right), \\
& M_{2}=\frac{A_{b}}{m} \frac{\beta_{e}}{A_{c} x_{c}+V_{0}} K_{2}\left(p_{c}\right), \\
& M_{3}=\frac{A_{b}}{m} \frac{\beta_{e}}{A_{c} x_{c}+V_{0}} A_{c} \dot{x}_{c} .
\end{aligned}
$$

Then

$$
\begin{aligned}
& r_{1}=\dot{x}_{c}^{*}, \\
& r_{2}=\ddot{x}_{c}^{*} .
\end{aligned}
$$

By (45) and (47),

$$
\begin{aligned}
& \dot{e}_{1}=e_{2}, \\
& \dot{e}_{2}=\dot{r}_{2}-M_{1} \tau+M_{2}+M_{3}+\frac{c_{c}}{m} x_{2}+\frac{k_{c}}{m} x_{1} .
\end{aligned}
$$

Substituting (48) into (28),

$$
\begin{aligned}
\tau= & \frac{1}{M_{1}}\left[\varepsilon \operatorname{sgn}(s)+k s+M_{2}+M_{3}+\frac{c_{c}}{m} x_{2}+\frac{k_{c}}{m} x_{1}\right. \\
& \left.+\dot{r}_{2}+c e_{2}\right] .
\end{aligned}
$$

Here the proof of tracking stability is given. 


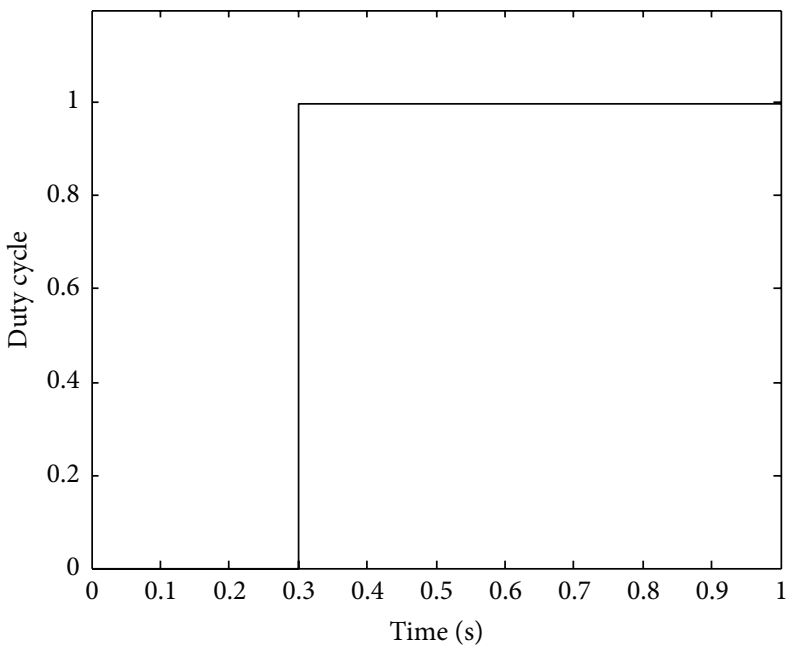

(a) Step-input condition

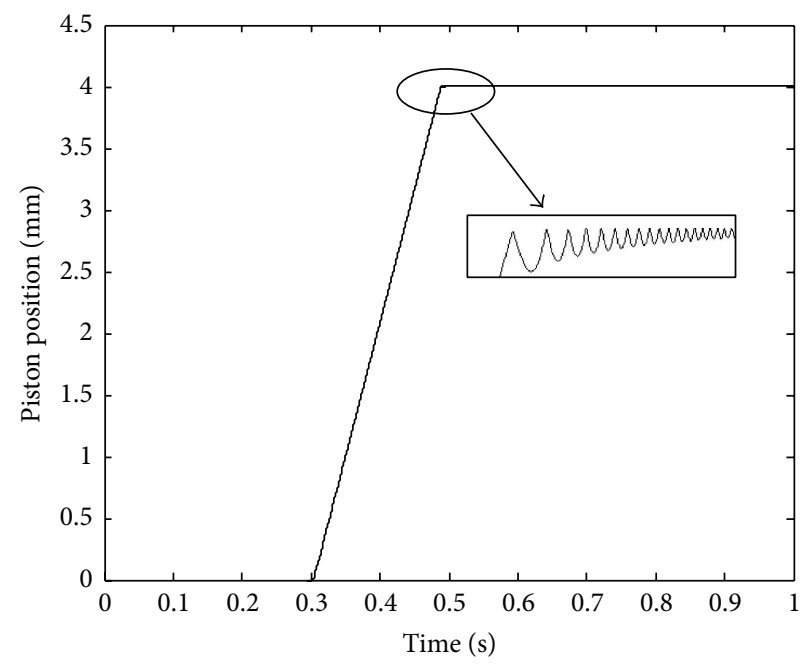

(c) Piston position

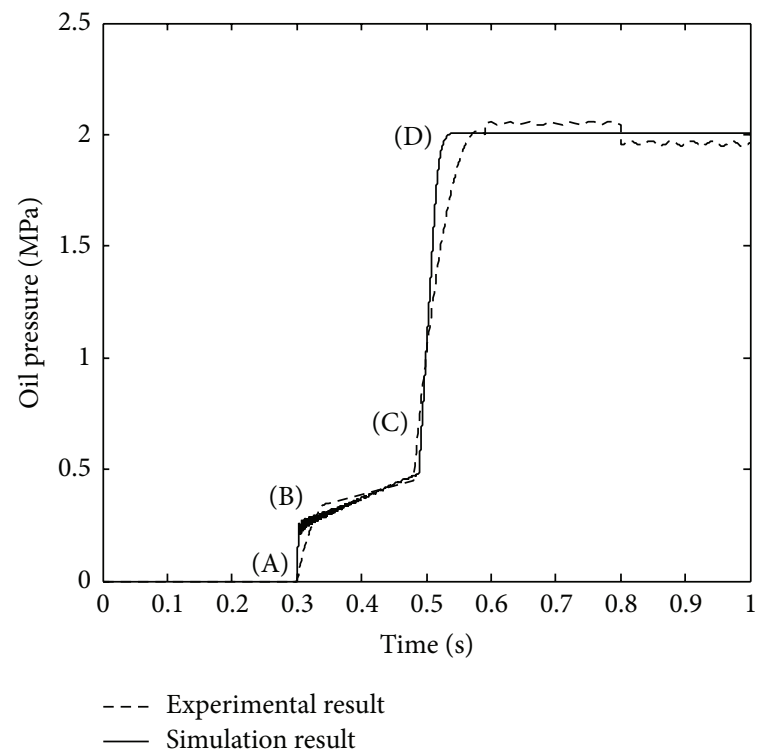

(b) Oil pressure

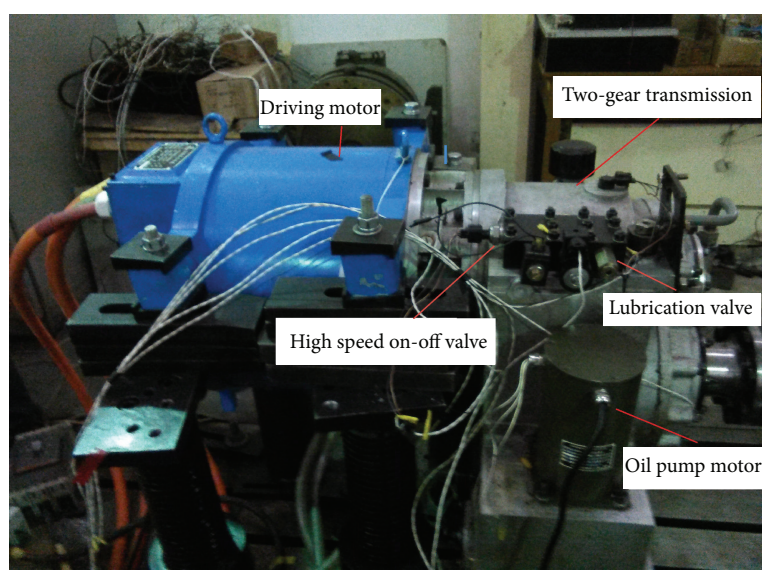

(d) Experiment platform

FIGURE 5: Results of simulation and experiment in oil charging process.

Define the Lyapunov function as

$$
V=\frac{1}{2} s^{2}
$$

\section{Then}

$$
\begin{aligned}
\dot{V}= & s \cdot \dot{s} \\
= & s \\
& \quad\left(c e_{2}+\dot{r}_{2}-M_{1} \tau+M_{2}+M_{3}+\frac{c_{c}}{m} x_{2}+\frac{k_{c}}{m} x_{1}\right) .
\end{aligned}
$$

Substituting (39) into (41),

$$
\begin{aligned}
\dot{V}= & s \cdot\left\{c e_{2}+\dot{r}_{2}+M_{2}+M_{3}+\frac{c_{c}}{m} x_{2}+\frac{k_{c}}{m} x_{1}-M_{1}\right. \\
& \cdot \frac{1}{M_{1}}\left[\varepsilon \operatorname{sgn}(s)+k s+M_{2}+M_{3}+\frac{c_{c}}{m} x_{2}+\frac{k_{c}}{m} x_{1}\right. \\
& \left.\left.+\dot{r}_{2}+c e_{2}\right]\right\}=s \cdot[-\varepsilon \operatorname{sgn}(s)-k s]=-\varepsilon \cdot|s|-k s^{2} \\
& =-\left(\frac{\varepsilon}{2} \sqrt{V}+\frac{k}{2} V\right) \leq 0 .
\end{aligned}
$$

Proof is completed. 


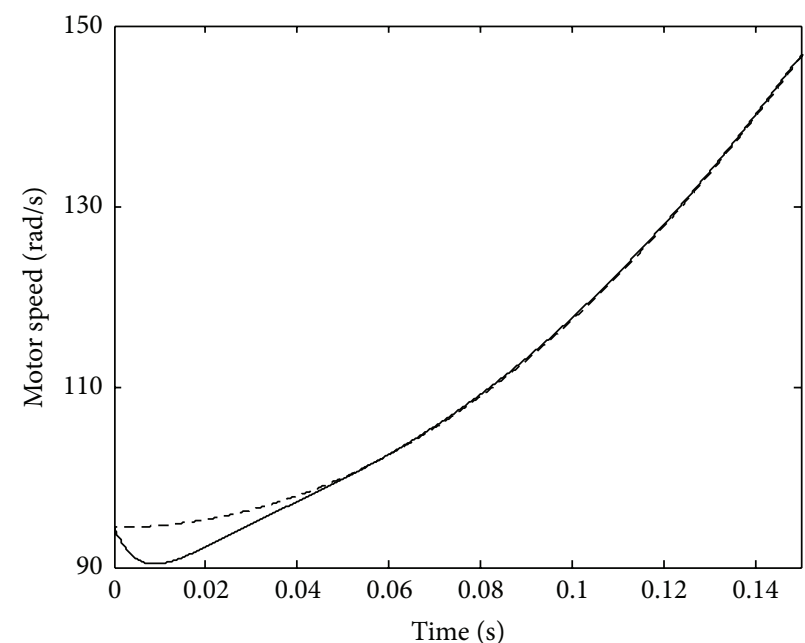

Sliding mode control - - Optimal trajectory

(a) Clutch disengagement phase

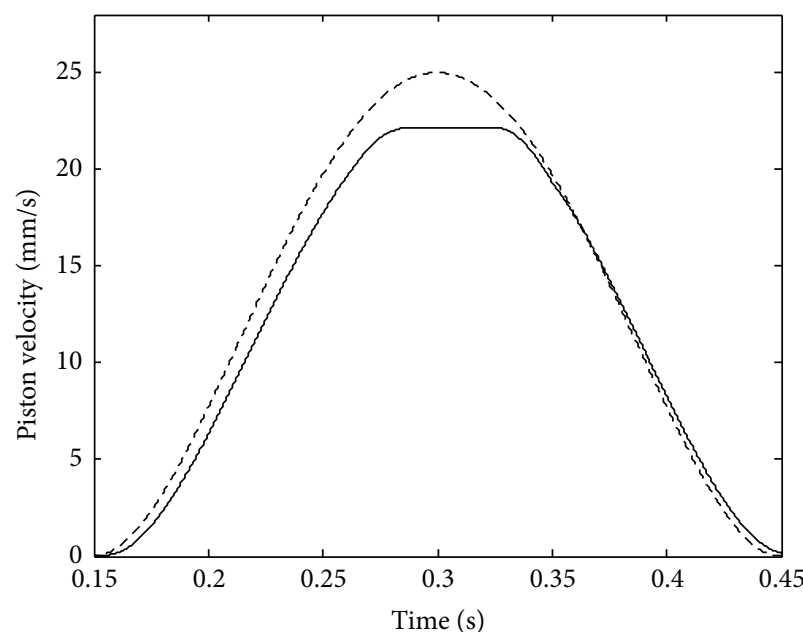

Sliding mode control - - Optimal trajectory

(b) Free phase

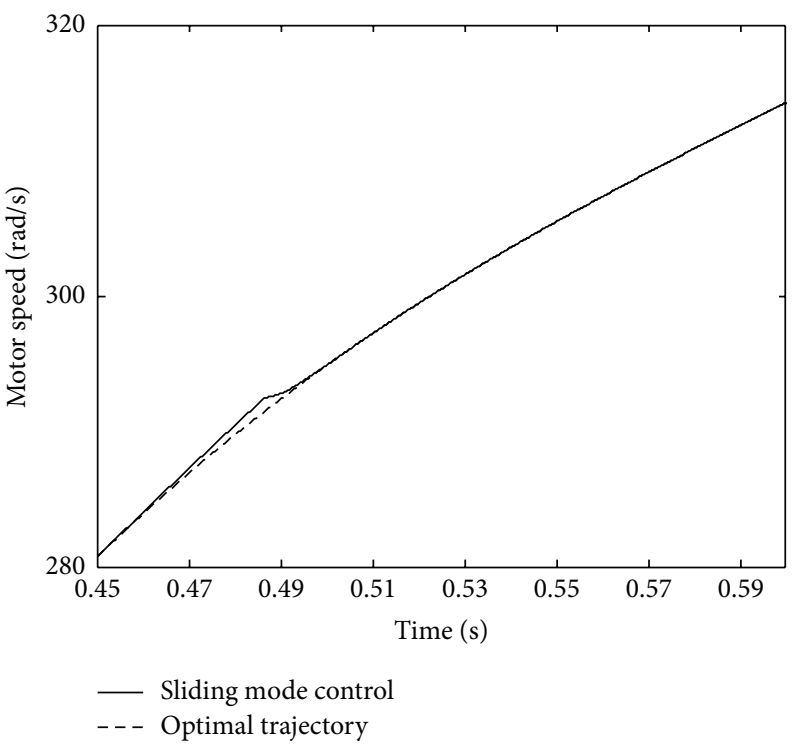

(c) Brake engagement phase

Figure 6: Tracking results of state variables.

\section{Result Analysis of Simulation and Experiment}

In this paper, the simulation models of hydraulic system and sliding mode controller of two-gear transmission are built in MATLAB/simulink. An experiment platform is built to verify the model of hydraulic system. On this basis, the trajectory tracking of oil pressure in downshift process is analyzed by simulation.

4.1. Model Verification of Hydraulic System. Parameters of hydraulic system are shown in Table 1. A kind of stepinput condition of duty cycle is designed to analyze the
TABle 1: Parameters of hydraulic system.

\begin{tabular}{lccc}
\hline$R_{1 c} / R_{2 c} /(\mathrm{mm})$ & $89 / 135$ & $R_{1} / R_{2} /(\mathrm{mm})$ & $86 / 119$ \\
$\mu_{\text {seal }}$ & 0.1 & $b_{c} /(\mathrm{mm})$ & 7 \\
$V_{c 0} /\left(\mathrm{mm}^{3}\right)$ & $1.13 \times 10^{5}$ & $m_{c} /(\mathrm{kg})$ & 6.82 \\
$k_{c} /(\mathrm{N} / \mathrm{mm})$ & 1844.5 & $x_{c 0} /(\mathrm{mm})$ & 4.2 \\
$x_{c \max } /(\mathrm{mm})$ & 4 & $\mu$ & 0.13 \\
$z_{\mathrm{cl}} / z_{\mathrm{br}}$ & $6 / 8$ & $p_{s} /(\mathrm{MPa})$ & 2 \\
$\rho /\left(\mathrm{Kg} / \mathrm{m}^{3}\right)$ & 875 & $k_{\text {non }}(\mathrm{N} / \mathrm{m})$ & $3.07 \times 10^{10}$ \\
\hline
\end{tabular}

characteristics in oil charging process of combined clutch. Results of simulation and experiment are shown in Figure 5. 
TABLE 2: Relevant parameters in vehicle shift process.

\begin{tabular}{lccc}
\hline Curb weight $/ \mathrm{Kg}$ & 15000 & Tire radius $/ \mathrm{m}$ & 0.478 \\
Gear ratio (Low/High) & $3.5 / 1$ & Teeth ratio $k$ & 2.5 \\
Throttle opening & $50 \%$ & Vehicle speed $/ \mathrm{km} / \mathrm{h}$ & 25 \\
Load toque $T_{f} / \mathrm{Nm}$ & 760 & Final gear ratio $i_{0}$ & 6.5 \\
\hline
\end{tabular}

As shown in Figure 5(b), the simulation result of oil pressure is basically consistent with experimental result. But the rising trend of experiment is obviously slower than simulation. This is mainly because of the neglect of oil temperature changing, route resistance of oil tube, and so forth. Overall, this experiment shows the validity of hydraulic system model. With further analysis, the characteristics of oil charging process are explained as follows:

(1) (A) (B) part is the clutch disengagement phase in which the initial tension of spring is eliminated. The piston can be viewed as static; namely, $x_{c}=0$. Clutch $C$ is in sliding friction condition in this phase.

(2) (B) (C) part is the free phase in which the clutch and brake are all in separating state. The piston moves to maximum position from original position. In this step-input work condition, high speed on-off valve works at "on" state in the whole shift process; the oil flows into cylinder rapidly so that it only takes $0.21 \mathrm{~s}$ for piston to move to maximum position.

(3) (C) (D) part is the brake engagement phase. Piston has reached maximum position and oil pressure keeps rising to systemic pressure rapidly. The mutual friction condition between the brake and ring gear turns into relative static condition gradually and then shift process is completed.

According to experiment result, it takes $0.24 \mathrm{~s}$ for oil pressure to rise to stable pressure. It means that the minimum time of completing the whole downshift process is no less than $0.24 \mathrm{~s}$. Due to the high speed of piston movement in the whole process, there is a violent shock of piston at the point of engagement, as shown in Figure 5(c). This further shows the importance for the control of piston movement in shift process.

\subsection{Simulation Analysis of Oil Pressure Tracking in Downshift} Process. In the previous research, based on optimal control theory, the optimal trajectory of oil pressure and piston movement have been obtained to be used as reference trajectory of slide mode controller in this paper. The trajectory tracking of oil pressure of three phases is, respectively, simulated. Relevant parameters in vehicle shift process are shown in Table 2 and tracking results of state variables are shown in Figure 6.

As shown in Figure 6, the tracking error is relatively large at the beginning of each phase but it comes to a steady state rapidly. This can well verify the stability of the sliding mode controller of this paper. Generally speaking, the state variables tracked in each phase can keep consistent with optimal trajectory, which can reflect the tracking effect of oil pressure indirectly.

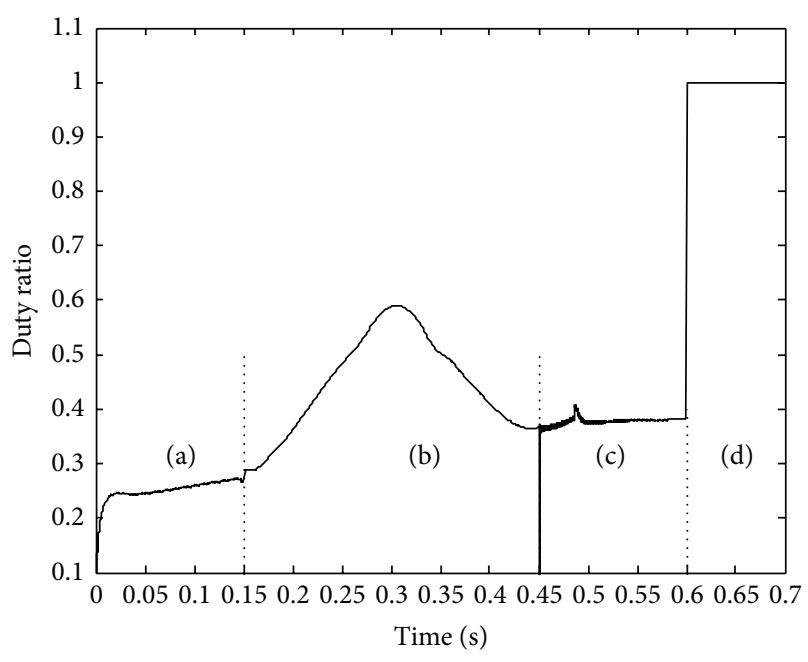

Figure 7: Duty cycle.

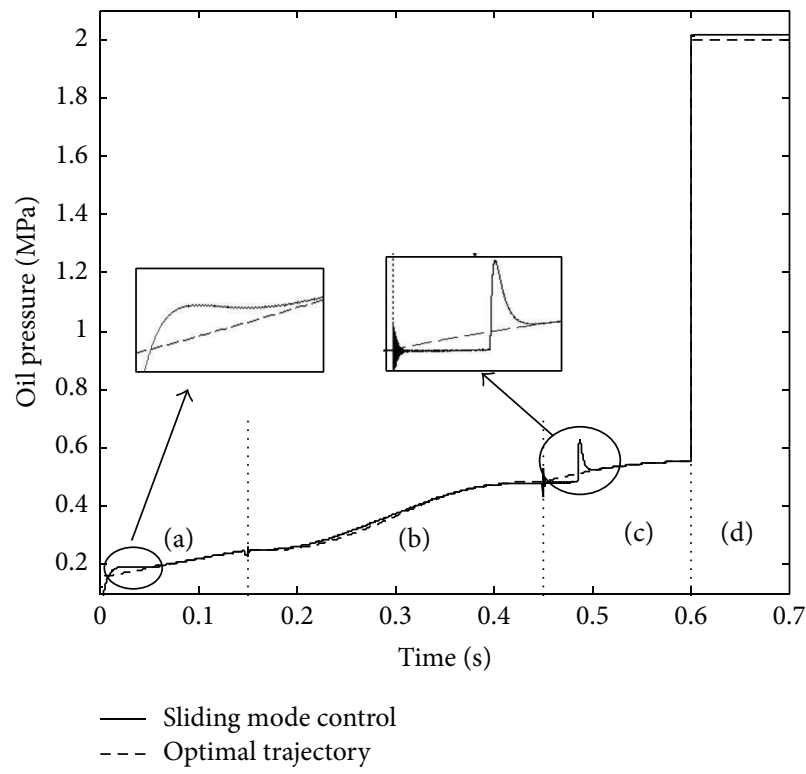

FIgURE 8: Oil pressure.

On the basis of sliding mode controller, combined with the model of hydraulic system, the duty cycle is worked out and shown in Figure 7 . The shift process is divided into four parts, (a), (b), (c), and (d), where (a), (b), and (c) are, respectively, clutch disengagement phase, free phase, and brake engagement phase; (d) is the phase that oil pressure rises to system pressure rapidly by setting a full duty cycle to provide sufficient toque reserve for combined clutch.

Figure 8 shows the tracking effect of oil pressure. At the beginning of each phase, there is fluctuation within a narrow range in oil pressure, which corresponds to Figure 6. In phase (d), compared with Figure 5(c), the oil pressure rises faster, which is because that system pressure $p_{s}$ is continuously low in the work condition of Figure 5 due to the fast oil charging process. However, there is enough time for the building-up of system oil pressure in Figure 7, so the oil pressure can rise to steady state rapidly. 


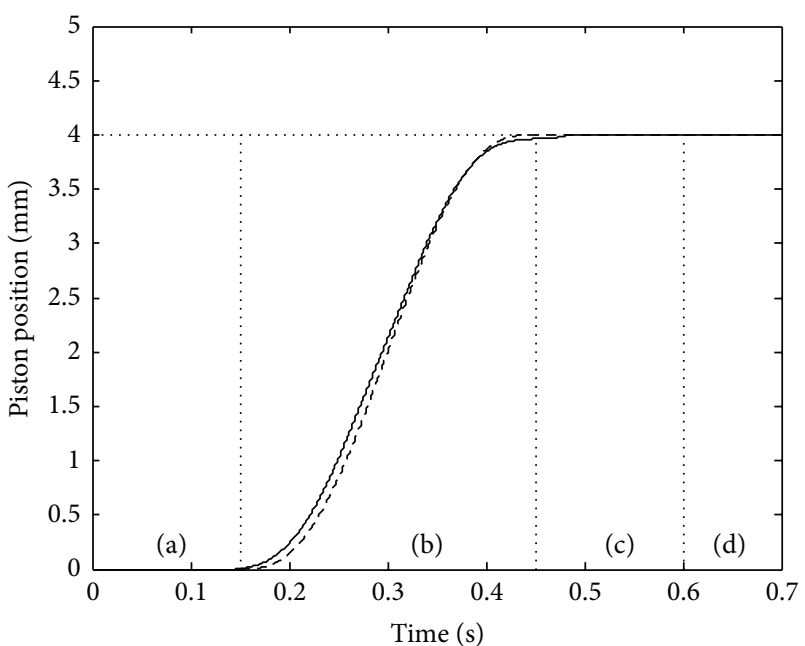

— Sliding mode control - - - Optimal trajectory

FIgURe 9: Piston position.

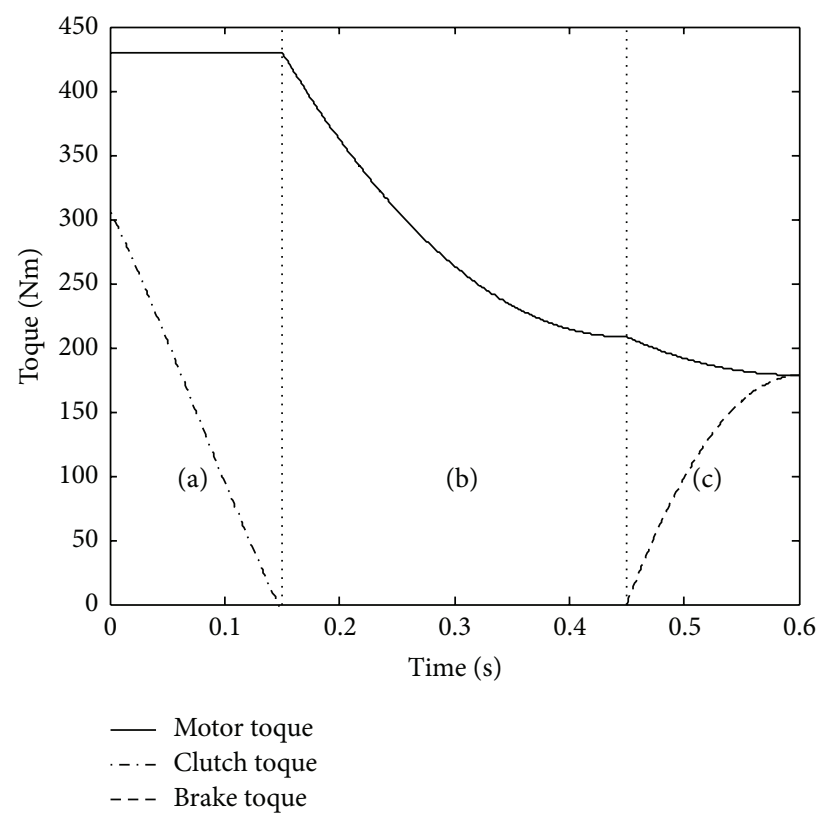

FIGURE 10: Transmission torque.

The tracking of piston position has good effect, as shown in Figure 9. To reduce the shock, the piston engages and disengages in low speed at the beginning and ending of free phase. To reduce interrupting time of power in shift process, the piston moves fast in the middle of free phase.

As shown in Figures 10-13, according to kinetic equations and basic parameters of complete vehicle (Table 2), the transfer torque of combined clutch, rotation speed of each component, friction work, and shift jerk are obtained. By the control of oil pressure, the clutch is disengaged completely at the end of phase (a); the brake is engaged completely at the end of phase (c). In downshift process, the power of ring gear is cut off, so the ring gear gradually slows down and stops at the end

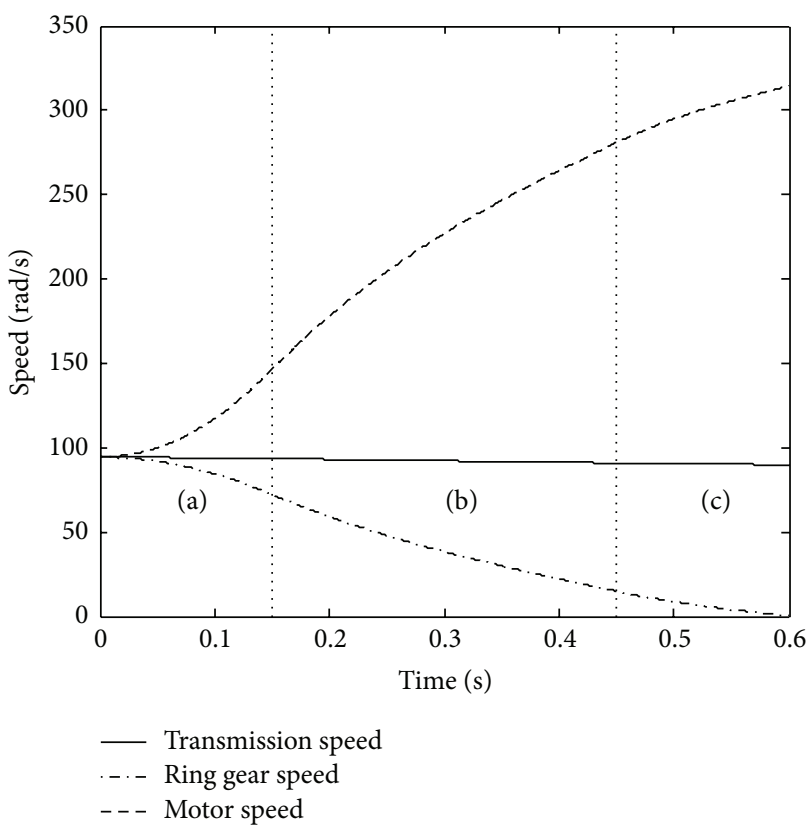

FIgURe 11: Rotation speed.

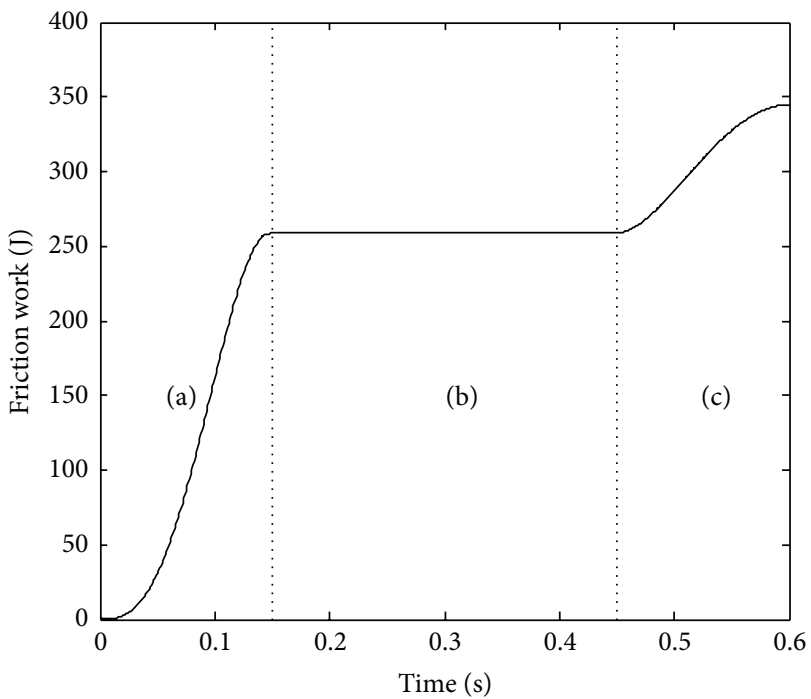

Figure 12: Friction work.

of shift process. Consequently, the slide friction of brake turns into static friction at the end. In phase (b), the constant power output of motor leads to the rapid rise of motor speed. In this phase, friction work and shift jerk are all close to zero. Shift jerk mainly exists in phase (a) and (c). Because the shift time is relatively short, there is no obvious change in output speed of transmission. The friction work of the whole shift process is about $350 \mathrm{~J}$; the peak shift jerk is about $3 \mathrm{~m} / \mathrm{s}^{3}$.

\section{Conclusion}

(1) The models of two-gear transmission and hydraulic system are, respectively, built in this paper. The relationship between duty cycle and oil pressure is 


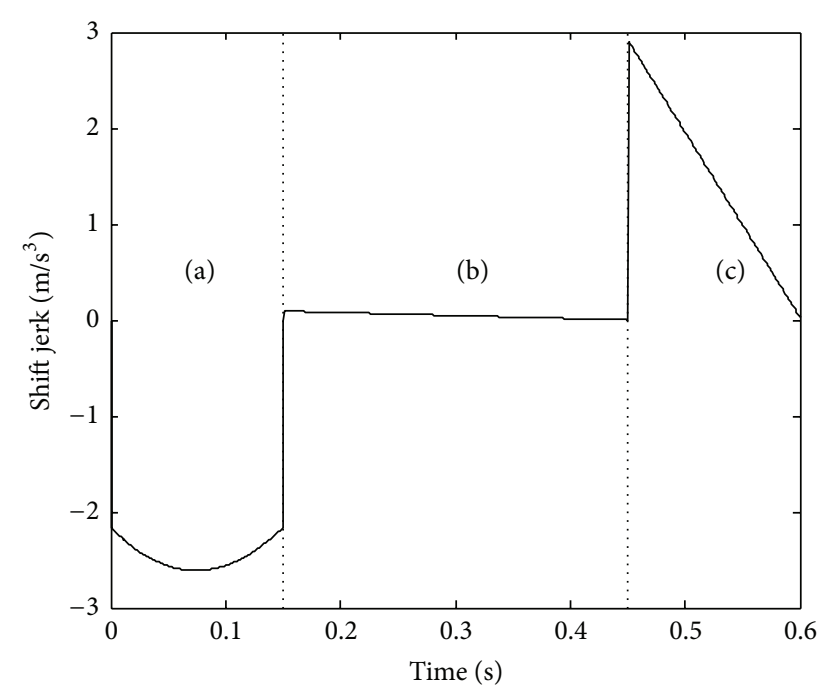

FIGURE 13: Shift jerk.

obtained. A step-input condition of duty cycle is designed to analyze the characteristic of oil charging process. An experiment platform is built to verify the validity and effectiveness of models.

(2) Aiming at the nonlinear characteristics of shift process and the problem of being unable to measure oil pressure, based on sliding mode control method, a tracking model of oil pressure is built. Combining with the model of hydraulic system, the tracking of oil pressure is simulated in three phases of shift process, respectively. Result shows that it can well and steadily track the optimal trajectory of oil pressure and improve shift quality effectively.

\section{Conflict of Interests}

The authors declare that there is no conflict of interests regarding the publication of this paper.

\section{Acknowledgment}

This work is supported by National Natural Science Foundation of China. The authors highly appreciate the above financial support.

\section{References}

[1] L.-L. Chen, H. Zhang, F. Ni, and J.-D. Zhu, "Present situation and development trend for construction of electric vehicle energy supply infrastructure," Journal of Modern Power Systems and Clean Energy, vol. 35, no. 14, pp. 11-17, 2011.

[2] M. Chen, B. Ma, G. Q. Li, and H. Y. Li, "Study on toque characteristic of multi-plate wet clutches during engagement," Journal of Huazhong University of Science and Technology, vol. 2014, no. 5, pp. 34-39, 2014.

[3] S.-J. Yang, S.-H. Yuan, and J.-B. Hu, "Study on dynamic performance in engagement process of wet clutch," Transactions of the Chinese Society of Agricultural Machinery, vol. 2005, no. 11, pp. 44-30, 2005.

[4] J.-Q. Li and H. Wei, "Coordinated control of downshift powertrain of combined clutch transmissions for electric vehicles," Mathematical Problems in Engineering, vol. 2014, Article ID 963725, 12 pages, 2014.

[5] Z.-G. Zhang, X.-J. Zhou, L. Shen, and Y.-J. Li, "Simulation and experiment on dynamic engagement characteristics of wet clutch," China Journal of Highway and Transport, vol. 23, no. 3, pp. 115-120, 2010.

[6] H.-W. Wang, X.-Q. Zhang, J.-L. Zhang, and B. Ma, "Simulation of thermal load of a wet clutch," Transaction of Beijing Institute of Technology, vol. 33, no. 1, pp. 47-51, 2013.

[7] X. S. Cheng, W. Feng, Z.-H. Lu, X. Liu, and Q. Gu, "Starting control of wet double clutch transmission," Journal of JiangSu University, vol. 2010, no. 2, pp. 145-149, 2010.

[8] E.-L. Wang, G. Tao, L. Chen, and H.-Y. Chen, "Oil pressure control for shifting process of off-road vehicle with high-power automatic transmission," Acta Armamentarii, vol. 2013, no. 2, pp. 137-142, 2013.

[9] J. Wang, H.-Y. Chen, G. Tao, and P. Gong, "Research on shift quality of automatic transmission," Transactions of the Chinese Society for Agricultural Machinery, vol. 2008, no. 2, pp. 38-42, 2008.

[10] J.-Z. Zhang, L.-F. Wang, and A.-L. Ge, "Study on the control law of automated mechanical transmission clutch," Chinese Journal of Mechanical Engineering, vol. 35, no. 3, pp. 37-40, 1999.

[11] D.-X. Xue, X.-W. Feng, L.-Z. Zheng, and C. Cao, “The fuzzy selfadaptive PID control of CVT's multiplate wet clutch based on the optimal pressure," Automotive Engineering, vol. 30, no. 5, pp. 424-428, 2008.

[12] P.-F. Qian, G.-L. Tao, D.-Y. Meng, W. Zhong, W. Ban, and $\mathrm{X}$. Zhu, "Sliding mode trajectory tracking control of electropneumatic clutch actuator," Journal of Zhejiang University, vol. 2014, no. 6, pp. 1102-1113, 2014.

[13] D.-T. Qin and Q.-H. Chen, "Universal clutch starting control of AMT/DCT automatic transmission based on optimal control," Journal of Mechanical Engineering, vol. 2011, no. 12, pp. 85-91, 2011.

[14] S. Chengshun and Z. Jianwu, "Optimal control applied in automatic clutch engagements of vehicles," Chinese Journal of Mechanical Engineering, vol. 17, no. 2, pp. 280-283, 2007.

[15] R. Mustafa, T. Kassel, G. Alvermann, and F. Küçükay, "Modelling and analysis of the electro-hydraulic and driveline control of a dual clutch transmission," in Proceedings of the FISITA World Automotive Congress, Budapest, Hungary, May-June 2010.

[16] M. Goetz, M. C. Levesley, and D. A. Crolla, "Dynamics and control of gearshifts on twin-clutch transmissions," Proceedings of the Institution of Mechanical Engineers, Part D: Journal of Automobile Engineering, vol. 219, no. 8, pp. 951-963, 2005.

[17] L. He, L. Li, L. Y. Yu, and J. Song, "Nonlinear sliding mode control of switched systems on continuously variable transmission shifting," International Journal of Vehicle Design, vol. 62, no. 2-4, pp. 289-311, 2013.

[18] G. Chen, W.-G. Zhang, and X.-N. Zhang, "Speed tracking control of a vehicle robot driver system using multiple sliding surface control schemes," International Journal of Advanced Robotic Systems, vol. 10, article 90, 2013. 


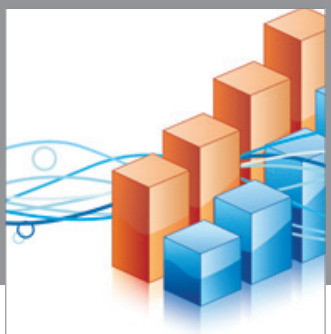

Advances in

Operations Research

vatem alat4

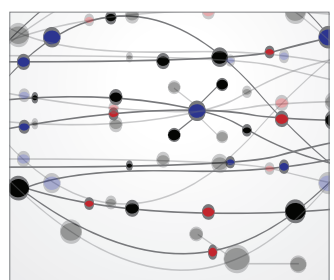

\section{The Scientific} World Journal
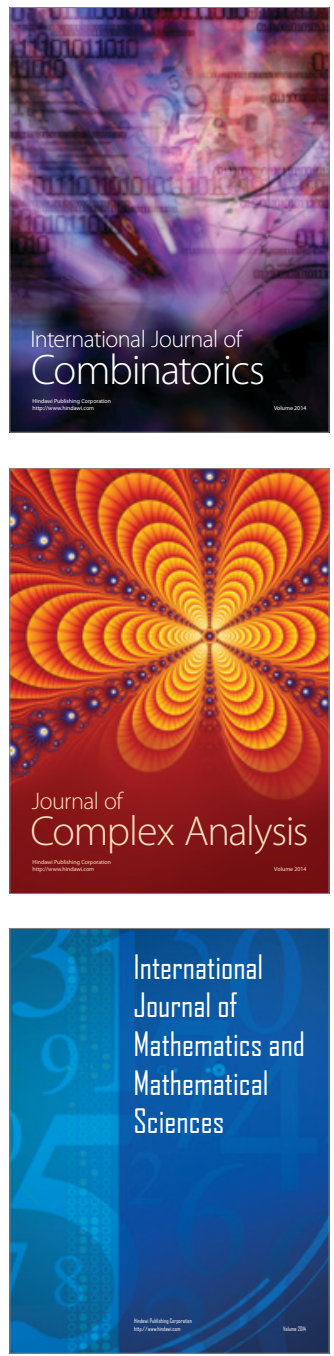
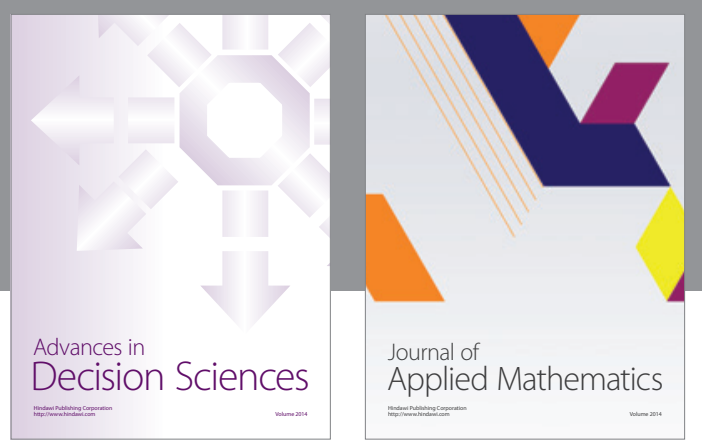

Algebra

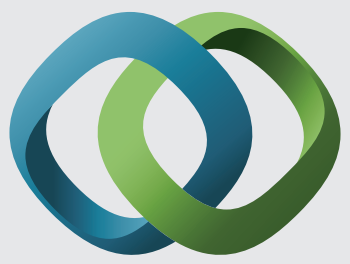

\section{Hindawi}

Submit your manuscripts at

http://www.hindawi.com
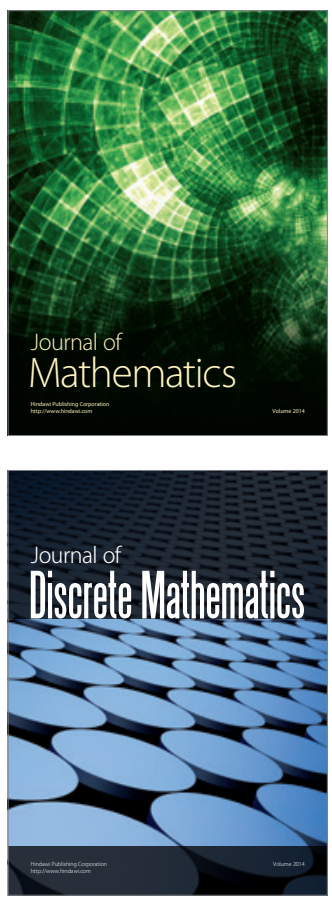

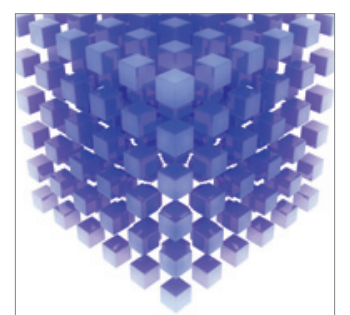

Mathematical Problems in Engineering
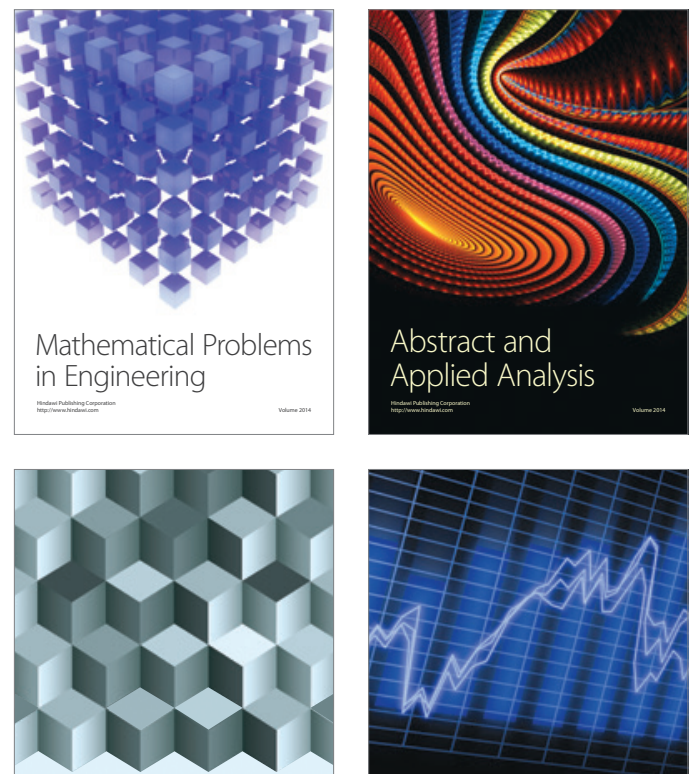

Journal of

Function Spaces

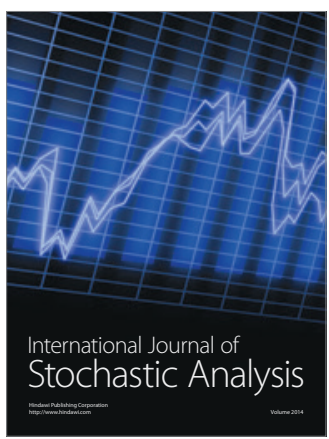

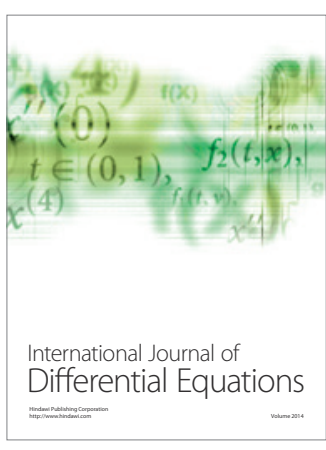
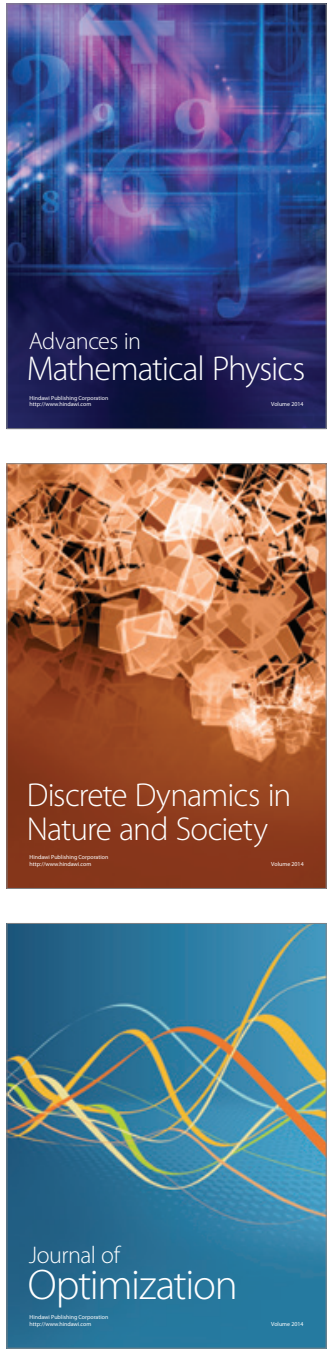